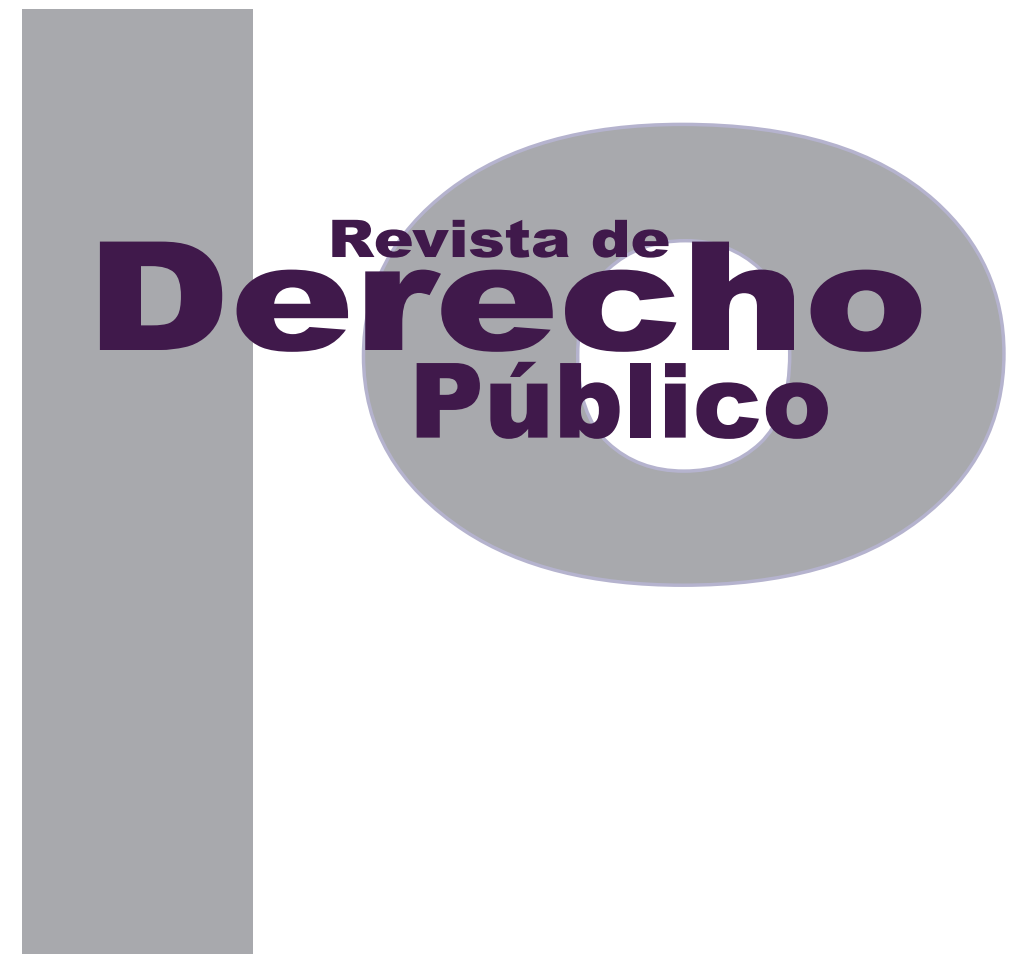

\title{
LA EXCEPCIÓN DE INCONSTITUCIONALIDAD EN EL ORDENAMIENTO JURÍDICO COLOMBIANO. APROXIMACIONES ELEMENTALES PARA SU ESTUDIO Y COMPRENSIÓN
}

\author{
Edgar ANDRÉS QUIROga NATALE
}

\section{Revisión de tema}

DOI: http://dx.doi.org/10.15425/redepub.34.2015.30

Universidad de los Andes

Facultad de Derecho

Revista de Derecho Público N. ${ }^{\circ} 34$

Enero - Junio de 2015. ISSN 1909-7778 


\title{
La excepción de inconstitucionalidad en el ordenamiento jurídico colombiano. Aproximaciones elementales para su estudio y comprensión
}

\section{Resumen}

La excepción de inconstitucionalidad en Colombia, es entendida como una facultad - deber que tienen las autoridades para inaplicar una norma y en su lugar aplicar la Constitución, representa una eficaz herramienta jurídica- política de protección al principio de supremacía constitucional, garantizando (en el caso concreto) su jerarquía y materialidad dentro del sistema de fuentes del derecho.

No obstante su gran importancia, esta se encuentra desprovista de un desarrollo legal y reglamentario, y, ante este vacío normativo, ha sido la jurisprudencia quien ha establecido unas subreglas hermenéuticas para determinar su concepto, naturaleza, características, elementos, límites y forma de aplicación. El estudio de las referidas subreglas constituye en gran medida el objeto del presente análisis en calidad de aproximaciones elementales.

Palabras clave: Constitución, supremacía constitucional, control difuso de constitucionalidad y excepción de inconstitucionalidad.

\section{Unconstitutionality except in the Colombian legal system. Basic approaches to the study and understanding}

\begin{abstract}
The exception of unconstitutionality in Colombia, understood as a right - duty of the authorities to set aside a law and instead apply the Constitution, represents an effective legal tool in order to protect the constitutional supremacy ensuring ( in this case) its hierarchy and materiality within the sources of legal system.

Despite its importance, it is devoid of a legal and regulatory development due to this loophole, the jurisprudence has set sub hermeneutical rules to determine its concept, nature, characteristics, elements, limits and application. The study referenced sub-rules is largely the subject of this analysis as basic approaches.
\end{abstract}

Keywords: Constitution, constitutional supremacy, diffuse control of constitutionality and unconstitutionality exception.

\section{A exceção de inconstitucionalidade no ordenamento jurídico colombiano. Aproximações elementares para seu estudo e compreensão}

\section{Resumo}

A exceção de inconstitucionalidade na Colômbia, é entendida como uma faculdade - dever que têm as autoridades para não aplicar uma norma e em seu lugar aplicar a Constituição, representa uma eficaz ferramenta jurídica- política de proteção ao princípio de supremacia constitucional, garantindo (no caso concreto) sua hierarquia e materialidade dentro do sistema de fontes do direito.

Não obstante sua grande importância, esta se encontra desprovida de um desenvolvimento legal e regulamentário, e, ante a este vazio normativo, tem sido a jurisprudência quem tem estabelecido umas sub-regras hermenêuticas para determinar seu conceito, natureza, características, elementos, limites e forma de aplicação. 0 estudo das referidas subregras constitui em grande medida o objeto da presente análise em qualidade de aproximações elementares.

Palavras-chave: Constituição, supremacia constitucional, controle difuso de constitucionalidade e exceção de inconstitucionalidade. 


\title{
La excepción de inconstitucionalidad en el ordenamiento jurídico colombiano. Aproximaciones elementales para su estudio y comprensión*
}

\author{
Edgar Andrés Quiroga Natale**
}

\begin{abstract}
SUMARIO
Introducción - I. ANTECEDENTES - II. APROXIMACIÓN CONCEPTUAL Y NATURALEZA JURÍDICO-POLÍTICA - III. CARACTERÍSTICAS - A. Competencia in genere de aplicación - B. Se aplica a solicitud de parte o de forma oficiosa - C. Obedece a la existencia de unas condiciones objetivas de aplicación - D. Tiene efectos inter partes (regla general) - E. Se constituye en una institución distinta de la excepción de ilegalidad - F. Límites y deberes de aplicación - 1. Límites - 2. Deberes de aplicación - IV. CONCLUSIONES - Referencias.
\end{abstract}

Cómo citar este artículo: Quiroga Natale, E. A. (Junio, 2015). La excepción de inconstitucionalidad en el ordenamiento jurídico colombiano. Aproximaciones elementales para su estudio y comprensión. Revista de Derecho Público, 34. Universidad de los Andes (Colombia).

** Estudios de Doctorado en Derecho, Universidad Santo Tomás. Magíster en Derecho Económico, Universidad Externado de Colombia. Especialista en Justicia Constitucional y Protección Jurisdiccional de los Derechos Fundamentales, Universidad de Pisa (Italia). Especialista en Resolución de Conflictos y Estrategias de Negociación, Universidad Castilla La Mancha (España). Especialista en Derecho Administrativo, Universidad Santo Tomás. Especialista en Derecho Constitucional, Universidad Nacional de Colombia. Especialista en Pedagogía, Unad. Abogado (Magna Cum Laude), Universidad Pedagógica y Tecnológica de Colombia. Consultor y asesor jurídico externo de entidades públicas y privadas. Docente universitario: Externado de Colombia, Nacional de Colombia, Libre de Colombia, Santo Tomás, Juan de Castellanos, UPTC, entre otras. Correo: edgarandresq80@gmail.com 


\section{Introducción}

El Estado social de derecho no es una conquista estática que denota una manera muy particular de organización del poder político, económico, social, cultural y jurídico de una determinada sociedad; a contrario sensu, se constituye en una construcción dinámica y en constante redefinición ${ }^{1}$ que parte del establecimiento de unas instituciones formales que permean progresivamente las informales y se integran al tejido social de un colectivo.

Sobre el particular expone el nobel Douglas North:

Las instituciones son las reglas de juego en una sociedad o, más formalmente, los constreñimientos u obligaciones creados por los humanos que le dan forma a la interacción humana. En consecuencia, estas estructuran los alicientes en el intercambio humano, ya sea político, social o económico. El cambio institucional delinea la forma en que la sociedad evoluciona en el tiempo y es, a la vez, la clave para entender el cambio histórico (1990, pág. 3).

En ese ejercicio continuo y cambiante en la construcción del modelo, se observa una serie de etapas o estadios de diseño y articulación que pueden identificarse bajo las siguientes categorías:

1 En ese sentido enseña el profesor Upegui: "el concepto de Estado Social de Derecho en Colombia ha sido esquivo, sus contornos son poco claros, sus funciones diversas y sus usos discursivos múltiples. En varios intentos de aproximación a su definición abundan los lugares comunes y las referencias anacrónicas; su intensa carga valorativa lo hace difícil de manejar con rigor, sorprende por las trampas ideológicas que puede tender, y su característica de producto transcultural lo hace singularmente diverso" (2009, pág. 11). i. Fase de reconocimiento: mediante la cual se consagran a título normativo las limitaciones al detentador del poder, y, concomitante a ello, la estipulación de un "catálogo" de derechos y garantías para sus destinatarios.

ii. Fase orgánica: se evidencia en la creación de instituciones formales mediante las cuales se ha de materializar el ejercicio del poder político, garantizando su adecuada división y permitiendo una asignación funcional para identificar el ámbito de competencias.

iii. Fase material: caracterizada por la existencia de mecanismos idóneos y eficientes para la protección real y efectiva de los derechos de los miembros del colectivo.

La consagración del modelo social de derecho en Colombia a partir de la Constitución Política de 1991 no es ajena a la articulación de las fases en comento, en la medida que se puede identificar en su corpus:

a) Cláusulas de reconocimiento de derechos y garantías (derechos fundamentales, socialeseconómicos, colectivos y del medio ambiente y derechos innominados), así como cláusulas de restricción al ejercicio del detentador del poder, tales como la sujeción al respeto de la Constitución y las leyes, reducción del ámbito de discrecionalidad y el condicionamiento de actuación a los procedimientos previamente establecidos para el ejercicio del poder.

b) División del poder público y las instituciones por medio de las cuales se ha de materializar, con la corresponsal asignación de competencias. Se pueden identificar unas macrofunciones del poder público (ejecutiva, legislativa, 
judicial, fiscalizadora y electoral) así como la existencia de unos entes autónomos con régimen constitucional especial (Banco de la República, universidades, Comisión Nacional del Servicio Civil y corporaciones autónomas regionales), y, concomitante con ello, la consagración de cláusulas pro-legislatore de actuación y responsabilidad de los servidores públicos, con estricta observancia en el ámbito funcional.

c) Consagración de mecanismos de protección para la defensa de los derechos de los destinatarios del poder.

No obstante el diseño en referencia, la protección de los derechos de las personas en la realidad dista mucho de las consagraciones positivas contempladas en la Carta superior; es decir, una cosa es lo reconocido normativamente y otra muy distinta lo materializado en la realidad, generando en muchos casos la inoperancia material de la Constitución con todas las corresponsales consecuencias sociales, políticas, económicas, etc., que esto conlleva.

Tener una Constitución solo de papel, equivale de facto a no tenerla; por lo tanto, el reto actual del constitucionalismo debe girar en torno a cómo garantizar esos derechos ya reconocidos, y es precisamente en este punto en donde los mecanismos de protección y la forma como puede accederse a ellos cobran un protagonismo e importancia suma.

Son múltiples las vías o herramientas de protección constitucional, las cuales integramos en las siguientes categorías: a) Propositivas o de acción, es decir, aquellas que requieren de la acción formal de la persona, ciudadano o autoridad $^{2}$ para poner en funcionamiento al entramado institucional de protección, tales como el ejercicio del derecho de petición, la acción de tutela, acciones populares, acciones de grupo, acción de cumplimiento, habeas corpus, habeas data, acción pública de inconstitucionalidad, acción de nulidad por inconstitucionalidad y acción constitucional de pérdida de investidura; b) Exceptivas o de inaplicación, grupo al que pertenecen aquellos mecanismos con que cuentan las autoridades públicas para proteger la Constitución, a partir de la inaplicación de otras normas en virtud del principio de supremacía constitucional.

A esta última categoría enunciada (exceptivas), se encuentra adscrita la figura de la excepción de inconstitucionalidad, la cual ha de fungir como objeto del presente estudio a partir del desarrollo de los siguientes acápites: i) Antecedentes, ii) Aproximación conceptual y naturaleza jurídico-política, iii) Características, iv) Límites y deberes de aplicación, y, a título de corolario, la presentación de unas v) Conclusiones.

\section{ANTECEDENTES}

La excepción de inconstitucionalidad en el ordenamiento jurídico colombiano tiene antecedentes próximos en la Constitución de 1886 (reformada por el Acto Legislativo 03 de 1910), y nace más como una necesidad política de mo-

2 Tal como la intervención de los personeros, defensores del pueblo o procuradores, quienes bajo competencia funcional están llamados a interponer acciones constitucionales para la protección de los derechos de las personas. 
rigerar los efectos de la excesiva concentración del poder por parte del detentador de la época, que de la misma evolución en nuestra tradición jurídica ya sea a título de desarrollo legislativo o progresismo judicial. $^{3}$

El artículo 6 de la Ley 153 de 1887 reflejaba de manera clara el lugar que la Constitución tenía dentro del sistema de fuentes y jerarquía normativa del ordenamiento para el constitucionalismo de ese momento. La Constitución cumplía una función de "legitimación ex-post" de la ley, la cual gozaba de presunción de constitucionalidad solo por el hecho de haber sido expedida con posterioridad a la entrada en vigencia de la Constitución de 1886. El texto del artículo en comento afirmaba:

Una disposición expresa de ley posterior a la Constitución se reputa constitucional, y se aplicará aun cuando parezca contraria a la Constitución. Pero si no fuere disposición terminante, sino oscura ó deficiente, se aplicará en el sentido más conforme con lo que la Constitución preceptúe.

Lo anterior genera un sistema de sujeción directa de las disposiciones contendidas en las leyes, y, concomitante con ello, una prohibición de inaplicación so pretexto de considerar que estas puedan atentar contra la Constitución, originando que la inaplicación de una ley solo sea posible previa existencia de derogatoria por el propio Congreso.
Resulta importante recordar que la Constitución colombiana de 1886 fue producto de la propuesta e imposición que el Partido Nacionalista -fundado por Rafael Núñez- hiciera a partir de su propia concepción de lo que debía ser el Estado y sus instituciones, pero de ninguna forma surgió de un consenso pluralista que integrara diversas concepciones políticas; dicha Constitución tuvo su origen en el Consejo Nacional de Delegatarios convocado mediante el Decreto 594 de 1885, e integrado de tal forma que sus decisiones se correspondieran con el querer del partido vencedor, es decir, el Nacionalista. Al respecto comenta Carlos Restrepo:

En el nombramiento -no en la elección- del personal del Consejo, se tuvo el cuidado de balancear mecánicamente el número de representantes de la antigua filiación conservadora y de antigua filiación independiente (...) De ese modo, no hay exactitud al afirmar que en el Cuerpo Constituyente estuvieran representados dos partidos, el independiente y el conservador; lo estaba uno solo, el nuevo, el nacional, y de este solo partido es obra la Constitución de 1886 (1972, pág. 108).

Es decir, la Constitución de 1886 fue redactada para el mantenimiento de un partido en el poder, partido el cual tenía la mayoría en el Congreso; por lo tanto, el artículo 6 de la Ley 153 de 1887 aseguraba que las leyes aprobadas por esa mayoría partidista no pudieran ser desconocidas por quienes debían aplicarlas, ni siquiera bajo el argumento de sostener que estas podrían atentar contra la Constitución.

3 Como sí sucedió en otros países, por ejemplo en Estados Unidos a través de la célebre sentencia Marbury vs. Madison de 1803. 
Este "diseño institucional", unido a muchas otras consagraciones normativas, permitió que en los gobiernos de Miguel Antonio Caro y Rafael Núñez se excluyera y oprimiera a la oposición y a quienes estaban en contra del régimen político establecido:

El cierre de los medios de comunicación, el destierro de líderes políticos, la escasa participación en los cuerpos colegiados de representación y la Ley de los Caballos ejemplifican la exclusión y discriminación que tuvieron que afrontar los integrantes de la minoría (Maya, 2012, pág. 120).

La Constitución hasta ese momento no detentaba naturaleza de norma jurídica en sentido estricto, se constituía en una Carta Política mediante la cual se explicitaba de forma general la organización del poder público, se establecían los límites de las autoridades en el ejercicio del poder y se consagraban algunos derechos de los ciudadanos; no obstante la existencia de dicha consagración, la Constitución al no ser una norma en estricto sentido, no tenía la capacidad de generar una sujeción jurídica directa para la protección de los derechos, ya que estos requerían ser desarrollados por leyes posteriores para permitir su exigencia de cumplimiento y ser justiciables.

Tan evidente era la falta de sujeción directa de los "derechos constitucionales" que la misma Carta Política ordenó incorporar algunos de ellos al Código Civil, con el objeto de garantizar su aplicación preferente; es decir, de forma paradójica, para aumentar la protección de algunos derechos constitucionales, el constituyente de 1886 ordenó consagrarlos en la ley, hecho que supone un proceso de "legalización de los derechos constitucionales". Sobre el Particular María José Maya comenta:

Los constituyentes de 1886 habían rebajado los derechos constitucionales al rango de ley: para garantizar los derechos del Título III de la Constitución, el artículo 52 de la misma ordenó incorporarlos al Código Civil como título preliminar, bajo el entendido de que este estatuto tenía aplicación preferencial (Código Civil de la Unión 1873, Art. 10). A pesar de que el Código Civil gozara de una mayor jerarquía con respecto a otras leyes, el efecto sigue siendo el mismo: esta forma de protección reducía la garantía de los derechos constitucionales al nivel de la ley (2012, pág. 127).

En igual sentido Jaime Sanín afirma:

Obviamente esto no añadía nada a su fuerza, pues en virtud de esta disposición no se elevaba el título III a una categoría superior, sino que, por el contrario, se le colocaba en una norma de rango inferior (...) en teoría la Constitución era ley suprema, pero los jueces podían aplicar solamente la ley, no la Constitución; así, entonces para dar efectividad práctica a los derechos civiles y garantías sociales consagrados en la Constitución, era el caso incorporar tales disposiciones a la legislación ordinaria con base en las cuales debían producirse los pronunciamientos judiciales (1971, pág. 105).

El hecho de compartir la condición de exclusión, y en algunos casos de persecución, unido a la sistemática violación de los derechos de los partidos minoritarios o de oposición, impulsó a los liberales y a los conservadores históricos a for- 
mar una alianza estratégica para poder de manera conjunta perseguir la introducción de una reforma constitucional en donde se sintieran integrados los intereses de la Nación y no solo los del Partido Nacionalista. De esta alianza surge la "Unión Republicana" en 1909, como un partido político que buscaba abolir con las condiciones referidas, a través de reformas constitucionales, el ordenamiento que hizo posible los abusos cometidos por los gobiernos de Caro y Reyes.

Es así como producto de la Unión Republicana se impulsa la reforma constitucional materializada en el Acto Legislativo 03 de 1910, mediante el cual se introducen reformas estructurales a la forma como se configura y ejerce el poder público a partir de las ramas que lo integran: ejecutiva, legislativa y judicial.

Los artículos 40 y 41 del referido acto legislativo consagran por primera vez en la historia jurídica de Colombia el control de constitucionalidad, bajo las siguientes cláusulas normativas:

Artículo 40.- En todo caso de incompatibilidad entre la Constitución y la ley se aplicarán (sic) preferencia las disposiciones constitucionales. Artículo 41.- A la Corte Suprema de Justicia se le confía la guarda de la integridad de la Constitución. En consecuencia, además de las facultades que le confieren ésta y las leyes, tendrá la siguiente: Decidir definitivamente sobre la exequibilidad de los Actos Legislativos que hayan sido objetados como inconstitucionales por el Gobierno, o sobre todas las leyes o decretos acusados ante ella por cualquier ciudadano como inconstitucionales, previa audiencia del Procurador General de la Nación.
Las citadas disposiciones normativas introducen profundos cambios en el ordenamiento jurídico, sobre todo en lo que tiene que ver con el sistema de fuentes del derecho, en la medida que sin hacer una mención expresa de la condición normativa de la Constitución es claro que la ubica por encima de las leyes en el momento de su aplicación, generando i) un reconocimiento implícito del principio de soberanía constitucional y ii) una habilitación para inaplicar las leyes cuando estas sean contrarias a la Constitución, consagrando un sistema difuso de control de constitucionalidad.

Aunado a ello, asigna a la Corte Suprema de Justicia competencia funcional para decidir sobre la exequibilidad de los actos reformatorios de la Constitución objetados por el gobierno, y las demandas promovidas por los ciudadanos en contra de leyes o decretos acusados de ser inconstitucionales, configurando un sistema concentrado de constitucionalidad.

Las anteriores reformas permiten realizar un control de la ley por fuera del imperium del Congreso, y por esa vía que la configuración de determinadas mayorías coyunturales en el Parlamento evite hacer nugatorios los derechos ya reconocidos constitucionalmente, ni llegar a desconocerlos por parte de leyes posteriores, derogando así la presunción "pétrea” de constitucionalidad de las leyes explicitada en el artículo 6 de la Ley 153 de 1887.

Vemos cómo el surgimiento de la excepción de inconstitucionalidad no es una figura que se introduce de forma inconsciente o azarosa, a con- 
trario sensu, se corresponde con una realidad histórica y una necesidad de controlar el poder del presidente a través del manejo y dominio que este ejercía sobre las mayorías parlamentarias.

El artículo 40 del Acto Legislativo 03 de 1910 resulta ser, entonces, el origen normativo de la excepción de inconstitucionalidad en Colombia, imbricando una nueva forma de control en el ejercicio del poder público y un mayor balance entre la ramas y órganos que lo ejercen, lo cual ha de servir de antecedente para su posterior consagración, reconocimiento y desarrollo a partir de la Constitución de 1991.

\section{APROXIMACIÓN CONCEPTUAL Y NATURALEZA JURÍDICO-POLÍTICA}

Con la expedición de la Carta de 1991, Colombia se convierte en un verdadero Estado constitucional -por lo menos desde la consagración formal-, elevando a canon superior el principio de supremacía constitucional; ${ }^{4}$ a partir de esta máxima sustantiva se articula la doble naturaleza que le acompaña:

i. Política. La Constitución se erige como una Carta que funge de marco institucional para el desarrollo del poder público, fijando los límites de los detentadores del poder, los derechos de los destinatarios de este, y la manera como se articulan las instituciones dentro de la estructura del Estado.

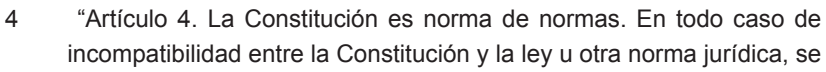
aplicarán las disposiciones constitucionales." ii. Jurídica. La Constitución se consagra como una norma jurídica a la cual se le reviste de carácter superior dentro del sistema de fuentes del derecho.

Por lo tanto, el concepto de Constitución tiene varios "usos" o significados, entre los cuales afirma el profesor Ricardo Guastini se encuentran los siguientes:

a) En una primera acepción, "Constitución" denota todo un ordenamiento político de tipo "liberal"; b) en una segunda acepción, "Constitución" denota un cierto conjunto de normas jurídicas: groso modo, el conjunto de normas -en algún sentido fundamentales- que caracterizan e identifican todo ordenamiento; c) en una tercera acepción, "Constitución" denota -simplemente- un documento normativo que tiene ese nombre (o un nombre equivalente); d) en cuarta acepción, en fin, "Constitución" denota un particular texto normativo dotado de ciertas características "formales", o sea, de un peculiar régimen jurídico (2007, pág.15).

En igual sentido, y haciendo referencia a la naturaleza jurídica de la Constitución, el profesor Fabio Pulido (2011) advierte la complejidad de dicho reconocimiento, en la medida que el concepto "norma" no es pacífico debido a su alto grado polisémico. Al respecto anota:

La ambigüedad de la palabra norma. La palabra norma es empleada para definir dos objetos con diferencias muy marcadas: (a) norma como texto legal, es decir enunciados lingüísticos que se encuentran dentro de un documento normativo; por otro lado, (b) el término norma se emplea para referirse al significado del texto legal -de la norma en el primer senti- 
do (R. Guastini, 1999). En la primera acepción, norma -como texto normativo- se refiere exclusivamente a aquellos documentos (y cada una de sus partes) que son considerados como fuentes formales de normas jurídicas (e.g. constitución, códigos, decretos etc.). Norma, según la segunda de las acepciones, puede ser de carácter conceptual, constitutivo y deóntico. Las normas conceptuales tienen por objeto definir términos legales, las constitutivas determinan quiénes tienen poderes normativos y las deónticas establecen como jurídicamente obligatorio, prohibido o facultativo un caso. La relevancia de dicha distinción radica en que los ordenamientos jurídicos están conformados por normas (en el segundo sentido) y no por textos (normas en el primer sentido) (pág. 167).

Otro ingrediente que suma complejidad a nuestra "arquitectura constitucional", es su ambigüedad semántica y sintáctica. Respecto del particular sostiene Humberto Sierra Porto:

Existe la denominada "ambigüedad semántica”, que se verifica cuando una palabra tiene más de un significado cuando es empleada en un texto legal con distintos alcances semánticos. A título de ejemplo de dicha ambigüedad, es posible citar la expresión "contribuciones" contenida en el artículo 338 de la Constitución: en sentido genérico, dicho vocablo denota "tributo", en sentido específico, significa "contribuciones parafiscales" (...) Otra peculiaridad de la interpretación constitucional en Colombia es la denominada "ambigüedad sintáctica", la cual se advierte siempre que un determinado precepto o enunciado pueda expresar más de una proposición dado que las conexiones entre las palabras que lo componen pueden interpretarse de distintos modos. Ejemplo de este tipo de ambigüedad es la derivada del artículo 42 de la Constitución, el cual establece las formas en que se constituye la familia en Colombia (2013, pág. 269).

Dentro de este marco general de comprensión de lo que entendemos por Constitución a partir de 1991, y, teniendo en cuenta que la excepción de inconstitucionalidad -como ya fue anotado en el acápite de antecedentes-, no cuenta con una reglamentación o desarrollo normativo más allá de su consagración en la Carta superior, la "tarea” de dar cuenta de una aproximación conceptual y de naturaleza, dos premisas importantes para el análisis de la institución, ha sido asumida en gran medida por la Corte Constitucional, la cual más allá de generar una pacífica y unificada definición, ha desarrollado la institución a partir de identificar unos elementos comunes que den cuenta de su corpus dogmático.

En reciente jurisprudencia el máximo intérprete constitucional abordó el tema en estudio en los siguientes términos:

Como primera medida, es importante aludir que el artículo $4^{\circ}$ de la Constitución Política establece que, cuando existen normas contrarias a la Constitución, se aplicarán las medidas contenidas en la Carta Política debido a su superioridad jerárquica. Lo anterior fundamenta el objeto de la figura conocida como excepción de inconstitucionalidad.

La jurisprudencia constitucional ha definido que "la excepción de inconstitucionalidad es una facultad o posibilidad (o si se quiere, una herramienta) de los operadores jurídicos, en tanto no tiene que ser alegada o interpuesta 
como una acción; pero se configura igualmente como un deber en tanto las autoridades no pueden dejar de hacer uso de ella en los eventos en que detecten una clara contradicción entre la disposición aplicable a un caso concreto y las normas constitucionales". En consecuencia, esta herramienta se usa con el fin de proteger, en un caso concreto y con efecto inter partes, los derechos fundamentales que se vean en riesgo por la aplicación de una norma de inferior jerarquía y que, de forma clara y evidente, contraría las normas contenidas dentro de la Constitución Política (CConst., SU132/2013, A. Estrada).

De la anterior cita jurisprudencial se desprenden varios elementos de análisis, tales como la naturaleza binaria o dual de la excepción de inconstitucionalidad (política y jurídica), lo cual se corresponde con la misma naturaleza binaria o dual de la Constitución a partir de la Carta de 1991.

En primer lugar, no se puede desconocer la naturaleza y función política de la excepción de inconstitucionalidad, toda vez que como fue expuesto en los antecedentes de la figura esta se erige como un instrumento que permite coadyuvar en la garantía del mantenimiento del equilibrio de los poderes públicos, y así evitar que una coyuntural mayoría del Parlamento profiera normas contrarias a la Constitución que impidiesen su inaplicación directa, como fue consagrado en el artículo 6 de la Ley 153 de 1887 ya comentado.

Sumado a lo anterior, la excepción de inconstitucionalidad es una expresión de la articulación entre el control constitucional y las formas de gobierno propias de un determinado Estado, con el objeto de contribuir al sistema de pesos y contrapesos en un diseño institucional; ${ }^{5}$ es decir, que para el mantenimiento del principio republicano de la separación de poderes públicos, la forma de gobierno de un Estado determina en gran parte quién puede o está facultado para hacer uso de esta figura.

En razón de lo anotado, por ejemplo, en Estados de corte parlamentario ${ }^{6}$ o semiparlamentario, ${ }^{7}$ el control de constitucionalidad es más proclive al reconocimiento de modelos concentrados y más limitado respecto de sus competencias o prerrogativas, en atención a la confianza o legitimidad que se deposita en las corporaciones legislativas, dando como consecuencia que la excepción de inconstitucionalidad en la mayor parte de estos modelos sea inexistente o se consagre pero solo como prerrogativa exclusiva de los tribunales constitucionales en uso directo del control a las leyes; a contrario sensu, en los Estados de corte presidencial, ${ }^{8}$ caracterizados por la transferencia de grandes prerrogativas al ejecutivo ${ }^{9}$-llegando en algunos inclusive, excepcionalmente, a detentar competencias le-

5 Argumento expuesto por el profesor Marc Carrillo en la clase impartida en la Especialización de Justicia Constitucional y Protección Jurisdiccional de los Derechos Fundamentales, el día 20 de enero de 2014 en la Universidad de Pisa (Italia).

6 Como en el caso de Inglaterra.

7 Tal como Francia, Austria y Portugal.

8 Modelo hegemónico en América Latina, como el caso colombiano.

9 Por ejemplo, el presidente de la República de Colombia es jefe de Estado, jefe de Gobierno, primera autoridad administrativa, comandante en jefe de las Fuerzas Armadas, etc. 
gislativas- $-{ }^{10}$ resulta más regular la imbricación de modelos de control difuso de constitucionalidad, habida cuenta de la necesidad de controlar ese gran poder directo del presidente, así como el poder ejercido de forma indirecta a través del control de las mayorías de este en el Parlamento. En estos modelos la excepción de inconstitucionalidad es de mayor aplicación no solo por parte de las Cortes o tribunales constitucionales, sino que tal herramienta puede ser utilizada de forma in genere por todos los jueces $-y$ en algunos casos como el colombiano también por autoridades administrativas- con el fin de proteger vía jurisdiccional el posible desbordamiento del poder del binomio presidente-parlamento.

Una segunda naturaleza de la excepción de inconstitucionalidad es la jurídica, la cual se traduce principalmente en la materialización del principio de la supremacía constitucional y el mantenimiento de la jerarquía de la Constitución en el sistema de fuentes del derecho; es decir, que la aplicación de la excepción permite que en un caso concreto y con efectos inter partes se deje de aplicar una ley o norma y en su lugar se aplique la Constitución, cuando estas de forma evidente y palmaria conculcan los valores, principios, fines, estructura, competencias y derechos constitucionales.

Al respecto expresó Hamilton:

Una Constitución es, en efecto, y debe ser observada por los jueces como una ley fun-

10 Explicitado en el caso colombiano en la posibilidad de expedir por parte del gobierno decretos legislativos, decretos extraordinarios y decretos con fuerza de ley. damental. Desde luego, a ellos corresponde determinarle su sentido, el sentido de toda ley particular emanada del cuerpo legislativo. $\mathrm{Si}$ se encuentra entre las dos una contradicción absoluta, aquella que tiene un carácter obligatorio y un valor superior debe naturalmente, ser preferida; o, en otros términos, la Constitución debe ser preferida a la ley, la intención del pueblo a la intención de sus agentes (1988, pág. 648).

En igual sentido escribió Alexis de Tocqueville:

El juez americano parece igual que los magistrados de otras naciones, sin embargo, está revestido de un inmenso poder político. ¿De dónde procede ese poder? (...) La causa reside en un solo hecho: los americanos han reconocido al juez el derecho de fundar sus sentencias en la constitución a preferencia de las leyes. En otros términos, ellos les han permitido no aplicar las leyes que les parezcan contrarias a la constitución (1981, pág. 169).

En resumen, la excepción de inconstitucionalidad en Colombia no es una acción, recurso o grado de jurisdicción en estricto sentido procesal; su naturaleza, como ha de abordarse más adelante, se corresponde con una facultad-deber de la autoridad dirigida a proteger una doble dimensión: i) Política, con el fin de coadyuvar a garantizar el equilibrio y separación de los poderes públicos; y ii) Jurídica, para garantizar el principio de supremacía constitucional en el caso concreto. ${ }^{11}$

\footnotetext{
11 Ya que para garantizar dicho principio a nivel general se utilizan vías de control concentrado, tales como la acción pública de inconstitucionalidad o la acción de nulidad por inconstitucionalidad.
} 


\section{CARACTERÍSTICAS}

Siguiendo la aproximación conceptual de construcción jurisprudencial expuesta en el apartado anterior, podemos decantar la existencia de las siguientes características de la excepción de inconstitucionalidad en el ordenamiento colombiano:

\section{A. Competencia in genere de aplicación}

A diferencia de la primera consagración de la figura sub examine estudiada a la luz del artículo 40 del Acto Legislativo 03 de 1910, que al estar imbricada en el Título XV correspondiente a la estructura y funciones de la Corte Suprema de Justicia podríamos afirmar que dicha competencia estaba dirigida con exclusividad a la Rama Judicial y en específico al referido órgano de cierre, la consagración de la excepción de inconstitucionalidad en la Constitución de 1991 se da en el artículo 4, el cual hace parte del Título I que se refiere a los "principios fundamentales" del Estado; por lo tanto, aunado a la obligación que tienen todas las autoridades públicas de todas las ramas de proteger la Constitución y garantizar sus fines en lo que corresponde a sus competencias, podemos concluir que dicha herramienta de protección de la supremacía constitucional puede ser utilizada por cualquier juez de la República - no solo por los órganos de cierre-, así como por las autoridades públicas en general -y particulares que cumplan funciones públicas o presten servicios públicos-que tengan en virtud de sus competencias que dar aplicación concreta a las normas jurídicas.
Con respecto al punto de quién puede ejercer la excepción de inconstitucionalidad, la Corte Constitucional se ha pronunciado a través de varias providencias entre las cuales se destacan las siguientes:

La jurisprudencia también es uniforme en señalar que la posibilidad de acudir a la excepción de inconstitucionalidad no está reservada únicamente a los jueces, sino que también se hace extensiva para las autoridades administrativas, no solo como una facultad, sino como un deber, cuando quiera que haya una clara incompatibilidad entre la Constitución y una norma de inferior jerarquía, prefiriéndose siempre la primera. Pero en materia de tutela esa figura es de recibo solamente si la aplicación de esas disposiciones contrarias a la Carta conlleva la violación de derechos fundamentales (T-357/2002, E. Montealegre).

De otra parte hay que tener en cuenta que el control por vía de excepción lo puede realizar cualquier juez, autoridad administrativa e incluso particulares que tengan que aplicar una norma jurídica en un caso concreto (C-122/2011, J. Henao).

De lo anterior se colige que la competencia para aplicar la excepción de inconstitucionalidad no recae en un criterio orgánico respecto de una rama del poder público a quien le esté asignada, por el contrario, se advierte que el constituyente se apoya en el criterio funcional al destinarle dicha facultad a quien tiene la competencia para aplicar normas.

Sobre el particular enseña el profesor Juan Manuel Charry: 
Para decidir sobre la excepción de inconstitucionalidad, es competente cualquier ejecutor jurídico que deba aplicar la ley. Pues la norma constitucional establece el deber para todas las personas de aplicar la Constitución en caso de incompatibilidad con la ley, razón por la cual no se comparten las tesis que restringen a determinado sujeto o funcionario la capacidad de aplicar preferentemente la Carta Fundamental (citado por Tobo, 1999, pág. 197).

En razón al criterio de asignación en comento, se decanta la importancia de la competencia funcional como uno de los pilares que edifican la estructura del ordenamiento jurídico que regula las relaciones de las autoridades del Estado entre sí, y de estas con los ciudadanos; por tanto, es un requisito sine qua non para el funcionamiento de un modelo de Estado que se reputa como social, constitucional y democrático de derecho.

La competencia, dentro del citado marco institucional cumple una doble función, a saber: i) Por una parte, funge como cláusula de restricción o límite al ejercicio del poder público respecto de quien lo detenta, y, ii) Por otra parte, sirve de garantía-derecho de los destinatarios del poder (soberanos) para que este sea ejercido dentro del marco del principio de legalidad en los procedimientos adelantados por las autoridades públicas.

El artículo 6 de la Constitución establece dos cláusulas de responsabilidad, de conformidad con la relación de sujeción con el poder público: i) Cláusula de responsabilidad pro libertate para los particulares, los cuales solo responderán por infringir la Constitución y las leyes (relación general de sujeción), y, ii) Cláusula pro legislatore para los servidores públicos, quienes además de lo anterior, responderán por omisión y extralimitación en el ejercicio de sus funciones (relación especial de sujeción).

Aunado a lo anterior, el canon 122 superior estipula que no habrá empleo público sin funciones expresamente detalladas en la ley o los reglamentos.

De los anteriores referentes normativos podemos decantar que la competencia funcional de los servidores públicos se encuentra profundamente reglada y restringida a las funciones exante asignadas en virtud de cláusulas directas (competencia originaria) o cláusulas habilitantes ex-post (competencia derivativa generada en virtud de delegación, avocación, subrogación, sustitución, subsidiariedad, etc.); por lo tanto, resulta de suma importancia dar cuenta de la habilitación funcional que acompaña el actuar de quien funge como servidor del Estado.

Conforme a lo anotado, se puede advertir con claridad que la excepción de inconstitucionalidad se traduce en la aplicación de un modelo de control de constitucionalidad "difuso extensivo", en la medida que permite a los jueces la inaplicación de las normas en el caso concreto tal como opera en el derecho norteamericano, pero adicional a ello, extiende esa competencia a quienes detentan la calidad de autoridades, categoría que de conformidad con el artículo 2 de la Ley 1437 de 2011 no solo son los servidores del Estado sino además también los par- 
ticulares que cumplen funciones públicas, y en virtud de dicha calidad les corresponde la tarea de dar aplicación a las normas jurídicas.

\section{B. Se aplica a solicitud de parte o de forma oficiosa}

En la medida que la excepción de inconstitucionalidad busca la protección del derecho objetivo dentro del marco del caso concreto, esta no se da solo a solicitud de parte, sino que es un deber ex-oficio de la autoridad ejercerla cuando advierta que la aplicación de determinada norma violaría de forma directa la Constitución. El máximo intérprete constitucional se ha referido a esta característica en los siguientes términos:

Debe tenerse en cuenta que no son las partes en el proceso, sino la misma Constitución, la que habilita al juez para hacer prevalecer el ordenamiento superior. Por ello, el hecho de que la excepción de constitucionalidad no sea alegada por una de ellas, no implica que su declaratoria no pueda hacerse directamente por el fallador. (...) En virtud de los argumentos anteriores, la jurisprudencia de esta Corporación ha concluido que la excepción de inconstitucionalidad puede aplicarse de oficio y que, en consecuencia, su utilización "no comporta un exceso en los límites materiales y personales del proceso en el cual ésta se verifica", como tampoco el desconocimiento del valor jerárquico normativo en que se estructura el ordenamiento jurídico (CConst., T-808/2007, C. Botero).

Este tipo de control se realiza a solicitud de parte en un proceso judicial o ex officio por parte de la autoridad o el particular al momento de aplicar una norma jurídica que en- cuentre contraria a la Constitución. En este caso se debe subrayar que la norma legal o reglamentaria que haya sido exceptuada por inconstitucional no desaparece del sistema jurídico y continúa siendo válida ya que los efectos del control por vía de excepción son inter partes, solo se aplican para el caso concreto y no anulan en forma definitiva la norma que se considera contraria a la Constitución (CConst., C-122/2011, J. Henao).

La citada jurisprudencia reafirma de forma clara, que la aplicación de la excepción no requiere de petitum expreso - ni siquiera cuando esta se aplica en el escenario del proceso judicial o administrativo-, ya que como se ha anotado, a pesar de que la misma se materializa y tiene efectos en el caso concreto, su ámbito político y jurídico se extiende a la protección del derecho objetivo sustancial y al control de los poderes públicos, razón por la cual es facultad-deber de la autoridad aplicarla cuando se corroboren las condiciones para su procedencia.

\section{Obedece a la existencia de unas condiciones objetivas de aplicación}

Con el objeto de evitar que la aplicación de la excepción de inconstitucionalidad se convierta en un instrumento de desobediencia a la ley, y de contera a las reglas propias de la democracia formal desbordando los límites de los poderes públicos, la Corte Constitucional colombiana ha desarrollado a través de su jurisprudencia unas condiciones objetivas que deben existir para la aplicación legítima de la excepción, las cuales son: i) Que exista una violación o contradicción clara, evidente y palmaria de la norma llamada a 
ser inaplicada con la Constitución configurándose claramente un estatus de incompatibilidad, y ii) Que la norma llamada a ser inaplicada sea una reproducción de otra previamente declarada inexequible o nula por inconstitucional.

Respecto de la exigencia de incompatibilidad manifiesta, la Corte se pronunció desde prematura jurisprudencia mediante la sentencia T-614 de 1992 de la siguiente forma:

Para que la aplicación de la ley y demás disposiciones integrantes del ordenamiento jurídico no quede librada a la voluntad, el deseo o la conveniencia del funcionario a quien compete hacerlo, debe preservarse el principio que establece una presunción de constitucionalidad. Esta, desde luego, es desvirtuable por vía general mediante el ejercicio de las aludidas competencias de control constitucional y, en el caso concreto, merced a lo dispuesto en el artículo $4^{\circ}$ de la Constitución, haciendo prevalecer los preceptos fundamentales mediante la inaplicación de las normas inferiores que con ellos resultan incompatibles.

Subraya la Corte el concepto de incompatibilidad como elemento esencial para que la inaplicación sea procedente, ya que, de no existir, el funcionario llamado a aplicar la ley no puede argumentar la inconstitucionalidad de la norma para evadir su cumplimiento.

El Diccionario de la Real Academia de la Lengua define la incompatibilidad en términos generales como "repugnancia que tiene una cosa para unirse con otra, o de dos o más personas entre sí".

En el sentido jurídico que aquí busca relievarse, son incompatibles dos normas que, dada su mutua contradicción, no pueden imperar ni aplicarse al mismo tiempo, razón por la cual una debe ceder ante la otra; en la materia que se estudia, tal concepto corresponde a una oposición tan grave entre la disposición de inferior jerarquía y el ordenamiento constitucional que aquella y este no puedan regir en forma simultánea. Así las cosas, el antagonismo entre los dos extremos de la proposición ha de ser tan ostensible que salte a la vista del intérprete, haciendo superflua cualquier elaboración jurídica que busque establecer o demostrar que existe (CConst., T-614/1992, J. Hernández).

En el mismo sentido, la Corte reitera la exigencia en estudio así:

A este respecto, resulta pertinente recordar que, si bien es cierto cabe la excepción de inconstitucionalidad en todo caso de manifiesta contradicción entre las disposiciones constitucionales y las leyes $u$ otras normas, con el fin de obtener la efectiva prevalencia de la Carta Política mediante su aplicación preferente (artículo $4^{\circ}$ C.P.), ello tan solo es posible cuando surge una oposición evidente, esto es, una verdadera e insoslayable incompatibilidad entre dos mandatos, uno de los cuales -el inferiortiene que ceder ante el precepto constitucional (CConst., T-063/1995, J. Hernández).

La inaplicación de una norma de jerarquía inferior con apoyo en el artículo 4 de la Carta supone necesariamente la incompatibilidad entre su contenido y el de los preceptos constitucionales. Si tal incompatibilidad no existe, no cabe la inaplicación y la circunstancia no es otra que la de incumplimiento o violación de los mandatos dejados de aplicar (CConst., C-600/1998, J. Hernández). 
En atención a la segunda hipótesis de condición objetiva de aplicación el máximo intérprete constitucional ha expresado que:

Según la jurisprudencia de esta Corporación, la excepción de inconstitucionalidad únicamente puede aplicarse cuando resulta incuestionable -conforme al texto de la disposición o clarísima jurisprudencia de la Corte Constitucional-que viola la Carta. (ii) que la norma que fue inaplicada corresponda a la reproducción de una declarada inexequible por la Corte Constitucional, en cuyo caso se verificaría la violación del artículo 243 de la Carta (CConst., A-015/2003, M. Monroy).

La exigencia de que existan unas condiciones objetivas de aplicación también ha sido estudiada y decantada por el Consejo de Estado, quien sobre el particular ha manifestado:

La aplicación de la excepción de inconstitucionalidad está condicionada a la existencia de una situación de incompatibilidad visible e indiscutible entre una norma Constitucional y una de inferior jerarquía, que obliga a preferir la primera en razón de su carácter fundante de todo el ordenamiento jurídico. (...) Esta exigencia se explica porque (...) la excepción de inconstitucionalidad, que busca preservar la supremacía de la norma superior, implica a su vez el sacrificio de otros principios constitucionales, como la presunción de constitucionalidad de la que gozan las leyes y demás normas del ordenamiento jurídico y del deber de obedecimiento de unas y otras por parte de todas las autoridades; por tanto, su invocación requiere argumentos de plena evidencia de incompatibilidad que justifiquen sin asomo de duda la necesidad de apartarse en un caso concreto de normas de inferior jerarquía a la Constitución. De lo contrario, en caso de existir dudas o argumentos plausibles a favor de la compatibilidad entre ambas normas, se impone el deber, también de raigambre constitucional, de aplicar la normatividad legal y reglamentaria vigente, que es un "principio que rige la operatividad del Estado de Derecho y hace posible el funcionamiento de las instituciones dentro del esquema de organización jurídico-política previsto en la Constitución." Ahora, valga aclarar que, evidenciada dicha incompatibilidad, la aplicación de la excepción de inconstitucionalidad se convierte en un deber y no una simple posibilidad discrecional del operador jurídico (CE, Consulta y Servicio Civil, 20 may. 2010, W. Zambrano).

En resumen, el uso de la excepción de inconstitucionalidad debe obedecer a unos criterios objetivos de aplicación tales como la manifiesta incompatibilidad de la norma llamada a ser inaplicada con la Constitución, o, la reproducción de una norma previamente declarada inexequible o nula por inconstitucionalidad; cualquiera de las dos condiciones deben estar presentes como requisito sine qua non para que la aplicación de la excepción de constitucionalidad se repute como legítima.

\section{Tiene efectos inter partes (regla general)}

Aunque como se ha hecho referencia, la aplicación de la excepción de inconstitucionalidad protege el ámbito del derecho objetivo, no obstante esa condición, sus efectos son inter partes, es decir, solo vinculan a las partes sujetas 
al caso concreto. Dicha característica ha sido reconocida y reiterada en varias providencias de la Corte Constitucional, entre las cuales se hace referencia a las siguientes:

La excepción (...) produce efectos sino respecto de ella, es decir, individuales. Por otra parte, a diferencia de la acción, la excepción de inconstitucionalidad no requiere de tribunales especiales, sino que puede ser conocida por los tribunales ordinarios (T-006/1994, V. Naranjo).

Así, en cuanto a su naturaleza jurídica, la excepción de inconstitucionalidad establecida en el artículo 4 de la C.P. es un mecanismo de control constitucional de carácter difuso, que opera cuando la autoridad judicial y excepcionalmente administrativa, a petición de las partes o de oficio, detecta un vicio de inconstitucionalidad en una norma de inferior jerarquía e inaplica la norma prefiriendo la Constitución solo para el caso en cuestión, es decir con efectos interpartes (C-803/2006, J. Córdoba).

En el mismo sentido, la Corte Constitucional a través de autos ha dado alcance a varias de las características de la excepción de inconstitucionalidad, y, en lo que respecta al efecto inter partes generado por la figura ha sostenido:

La definición acerca de si existe o no la incompatibilidad entre la norma inferior y las fundamentales debe producirse en el caso específico, singular, concreto, y en relación con las personas involucradas en el mismo, sin que pueda exceder ese marco jurídico preciso. Se habla entonces de un efecto inter partes, o circunscrito a quienes tienen interés en el caso. $Y$ la norma inaplicada no se afecta en su vigencia general, aunque, por motivo de la inaplicación, no haya producido efectos en el asunto particular del que se trata (A-015/2003, M. Monroy).

Producto de lo anterior, se decanta que la aplicación de la excepción de inconstitucionalidad no excluye el control ex-post que pueda hacer la Corte Constitucionalidad o el Consejo de Estado en ejercicio del control concentrado respecto de las normas sujeto de la inaplicación, en respuesta a una acción pública de inconstitucionalidad o de nulidad por inconstitucionalidad que se promueva sobre estas, ya que dicho control (el concentrado) tiene efectos erga omnes y se realiza de forma general y abstracta. En punto de lo anotado, la Corte Constitucional ha manifestado:

Considera la Corte que las excepciones de inconstitucionalidad que profieren las autoridades judiciales, administrativas o los particulares cuando tengan que aplicar una ley, no elimina la posibilidad que tiene la corporación de realizar el control de constitucionalidad de determinado precepto. (...) La Corte encuentra que teniendo en cuenta el artículo 241 de la C.P., la instancia última de control de constitucionalidad de las leyes en Colombia es la Corte Constitucional, de tal manera que las excepciones de constitucionalidad pueden ser acogidas o no por ésta Corporación, no configura un precedente vinculante y tiene preeminencia sobre los fallos particulares que se hayan dado por vía de excepción. Esta preeminencia de la jurisdicción constitucional sobre las decisiones particulares y concretas que se establecen a través de la excepción de constitucionalidad se justifica teniendo en cuenta que el control de constitucionalidad tiene efectos erga omnes y se realiza de forma general y abstracta. De 
igual forma se subraya que los efectos del fallo de constitucionalidad hacen tránsito a cosa juzgada y determinan en forma definitiva la continuidad o no de la norma dentro del sistema jurídico, efecto que da coherencia y seguridad jurídica al sistema jurídico colombiano (C-122/2011, J. Henao).

El Consejo de Estado en igual sentido se ha pronunciado respecto del alcance y efectos que genera la aplicación de la excepción de inconstitucionalidad coincidiendo en que esta institución, tal y como fue concebida por el constituyente, faculta para no aplicar en el caso concreto y en su lugar aplicar la Constitución, sin llegar a configurar una potestad derogatoria o de nulidad sobre la norma inaplicada. En ese sentido el máximo órgano de lo contencioso administrativo ha sostenido:

Cuando se invoca la enunciada excepción, los argumentos deben estar encaminados a evidenciar que una ley que ha sido utilizada en el proceso que se discute es contraria a la Constitución Política, para lograr que se inaplique en el fallo que se profiera, sin afectar su vigencia general, es decir, con efectos únicamente interpartes (CE, Contencioso Administrativo, 26 oct. 2009, M. Briceño).

En efecto, el fundamento de la llamada excepción de inconstitucionalidad, se encuentra en el artículo $4^{\circ}$ de la Carta Política, y se le califica como control de constitucionalidad concreto porque carece de la nota de generalidad que es propia del control en abstracto, puesto que la definición acerca de si existe o no incompatibilidad entre la norma inferior y las constitucionales debe producirse en el caso específico, singular, concreto, y en relación con las perso- nas involucradas en el mismo, sin que pueda exceder ese marco jurídico preciso. Se habla, por tanto, en este caso de un efecto inter partes, o circunscrito a quienes tienen interés en el caso (CE, Quinta, 14 dic. 2006, D. Quiñones).

No obstante, la prolija y coincidente producción jurisprudencial tanto de la Corte Constitucional como del Consejo de Estado reiterando los efectos inter partes de la aplicación de la excepción de inconstitucionalidad, encontramos que en algunas providencias del máximo intérprete constitucional se han dado efectos inter pares $^{12}$ a la aplicación de la figura sub-examine. Tal es el caso del Auto 071 de 2001 mediante el cual la Corte ordena inaplicar el Decreto 1382 de 2000 respecto de las normas de reparto imbricadas en esta norma, y en su lugar indica que debe aplicarse la regla de competencia contenida en el artículo 86 de la Constitución constituyéndose en una orden para todos los casos semejantes.

En igual sentido, mediante Auto 035 de 2009 el cual se expide en ejercicio del seguimiento al cumplimiento de la sentencia T-760 de 2008, se autoriza al Ministerio de Protección Social a utilizar la excepción de inconstitucionalidad en:

Los casos en que la aplicación de una norma de orden legal vulnere los derechos fundamentales de los usuarios del Sistema General de Seguridad Social en Salud, o de manera específica, inevitablemente resulte en un impedimento para la protección efectiva de estas personas.

12 Vinculando no solo a las partes en litigio sino a los demás casos semejantes. 
$(\ldots)$

Cuando ello sea necesario para lograr el goce efectivo del derecho a la salud y el cumplimiento de las órdenes contenidas en la sentencia T-760 de 2008 , de conformidad con lo señalado en la parte motiva del presente Auto.

La anterior autorización con un aliento extensivo no solo a los casos de examen sino a los que se encuentren en las mismas condiciones y además sin referirse o individualizar las normas sobre las cuales recaería puntualmente la excepción.

Estas últimas aplicaciones de la figura en estudio dejan una "puerta abierta" para que en casos especiales, y solo por parte de la Corte Constitucional, se aplique la excepción con efectos inter pares. Lo anterior no deja de ser polémico, ya que al no existir unas reglas normativas ni jurisprudenciales claras para el referido uso extensivo, se estaría generando por medio de la aplicación de la excepción de inconstitucionalidad un efecto equiparable a la declaratoria de inexequibilidad o nulidad, lo cual resulta contrario a la naturaleza y fines de la citada institución.

Por las características anotadas (salvo los casos especiales citados) respecto del efecto de la aplicación de la excepción de inconstitucionalidad, se puede concluir que dicha sujeción de vinculación particular y exclusivamente ceñida al caso concreto, le permite a la institución una suerte de autonomía teórica e independencia de otras figuras tales como la declaratoria de inexequibilidad, la declaratoria de nulidad por inconstitucionalidad y la misma suspensión provisional de los actos administrativos.

\section{E. Se constituye en una institución distinta de la excepción de ilegalidad}

El artículo 12 de la Ley 153 de 1887 establece que “las órdenes y demás actos ejecutivos del gobierno tienen fuerza obligatoria, y serán aplicados mientras no sean contrarios a la Constitución o a las leyes".

A partir de la norma en cita se llegó a decantar la posibilidad de inaplicar un acto administrativo en caso de que este fuera contrario a la Constitución o a la ley, haciendo uso no solo de la excepción de inconstitucionalidad sino además de la excepción de ilegalidad. ${ }^{13}$ No obstante, esta última posibilidad solo resultaba admisible en la medida que para la época de expedición de la Ley 153 no existía en Colombia el control de legalidad propiamente dicho, el cual nace para nuestro ordenamiento con la expedición del Decreto-Ley 01 de 1984 (antiguo Código Contencioso Administrativo); razón por la cual, se puede discernir que este último deroga tácitamente la disposición normativa del artículo 12 de la Ley 153 de 1887 haciendo actualmente nugatoria la posibilidad de aplicar la excepción de ilegalidad por parte de las autoridades públicas. ${ }^{14}$

\footnotetext{
13 Entendida como la facultad de inaplicar un acto administrativo (u otra norma de inferior jerarquía) por ser contraria a la ley.

14 Con excepción de los jueces, por las razones que se anotarán más adelante.
} 
Al respecto el máximo tribunal de lo contencioso administrativo se ha pronunciado de la siguiente forma:

Frente a la excepción de ilegalidad se ha considerado que el artículo 12 de la ley 153 de 1887, debe entenderse derogado tácitamente en atención a que dicha norma tuvo vigencia en una época en que No existía control efectivo de legalidad de los actos administrativos (CE, Cuarta, 14 jul. 1995, D. Gómez).

Conforme a lo anotado, resulta jurídicamente improcedente para las autoridades públicas inaplicar un acto administrativo (u otra norma de inferior categoría) aduciendo que este viola la ley, por cuanto esta condición de "ilegalidad" debe ser declarada por un juez administrativo, no solo por la presunción de legalidad que tienen los actos administrativos (lo cual hace parte de su fisiología), sino porque de permitir la aplicación de dicha figura se estaría pretermitiendo el control jurisdiccional de legalidad, violentando la teleología que inspiró su creación.

Sobre el particular la Corte Constitucional ha sostenido:

No hay en la Constitución un texto expreso que se refiera al ejercicio de la excepción de ilegalidad, ni a la posibilidad de que los particulares o las autoridades administrativas, por fuera del contexto de un proceso judicial, invoquen dicha excepción para sustraerse de la obligación de acatar los actos administrativos, sino que la Carta puso en manos de una jurisdicción especializada la facultad de decidir sobre la legalidad de los mismos, ilegalidad que debe ser decretada en los términos que indica el legislador. $(\ldots)$

La llamada excepción de ilegalidad se circunscribe entre nosotros a la posibilidad que tiene un juez administrativo de inaplicar, dentro del trámite de una acción sometida a su conocimiento, un acto administrativo que resulta lesivo del orden jurídico superior. Dicha inaplicación puede llevarse a cabo en respuesta a una solicitud de nulidad o de suspensión provisional formulada en la demanda, a una excepción de ilegalidad propiamente tal aducida por el demandado, o aún puede ser pronunciada de oficio. Pero, en virtud de lo dispuesto por la norma subexamine tal y como ha sido interpretado en la presente decisión, tal inaplicación no puede ser decidida por autoridades administrativas, las cuales, en caso de asumir tal conducta, podrían ser demandadas a través de la acción de cumplimiento, que busca, justamente, hacer efectivo el principio de obligatoriedad y de presunción de legalidad de los actos administrativos (C-037/2000, V. Naranjo).

De las anteriores referencias jurisprudenciales se coligen las siguientes diferencias entre la excepción de inconstitucionalidad y la excepción de ilegalidad:

i) La excepción de inconstitucionalidad se fundamenta en la protección y garantía del principio de supremacía constitucional; en cambio la razón que dio lugar al surgimiento de la excepción de ilegalidad fue servir de instrumento de garantía de sujeción a la ley cuando no existía en nuestro ordenamiento jurídico el control de legalidad propiamente dicho.

ii) Mientras la excepción de inconstitucionalidad tiene creación constitucional en el artículo 4 su- 
perior; la excepción de ilegalidad actualmente no cuenta con ninguna estipulación ni desarrollo normativo.

iii) La excepción de inconstitucionalidad puede ser aplicada por cualquier autoridad pública (o particulares que detentan la competencia de aplicación normativa); a contrario sensu, la excepción de ilegalidad solo puede ser aplicada por el juez administrativo dentro del marco del proceso.

\section{F. Límites y deberes de aplicación}

\section{Límites}

Del estudio hasta ahora desarrollado se puede desprender con claridad la existencia de algunos límites en el uso de la excepción de inconstitucionalidad, pues como fue anotado, dicha figura obedece a unos criterios objetivos de aplicación que circunscriben la forma como puede ser utilizada. Aunado a ello, resulta claro que las normas gozan de presunción de constitucionalidad, y el uso de la excepción genera una exigencia probatoria y de carga argumentativa para quien pretende desvirtuar con su aplicación dicha presunción en el caso concreto.

Del desarrollo jurisprudencial de la institución en estudio pueden establecerse a título enunciativo los siguientes límites:

i) Prohibición de aplicación de la excepción, si no existe una manifiesta incompatibilidad entre la norma llamada a ser inaplicada y la Constitución. ii) Prohibición de aplicación de la excepción, en caso de que la norma Ilamada a ser inaplicada haya sido objeto de una declaratoria de exequibilidad por parte de la Corte Constitucional o de validez por parte del Consejo de Estado en respuesta a una acción pública de inconstitucionalidad o nulidad por inconstitucionalidad según sea el caso. Respecto del particular la Corte Constitucional ha sostenido:

El juez puede aplicar válidamente la excepción de inconstitucionalidad en el caso concreto sin que para esto sea obstáculo las competencias de Corte Constitucional y Consejo de Estado para estudiar la constitucionalidad de una norma, con efectos erga omnes.

Una vez exista pronunciamiento definitivo de estas corporaciones en lo de su competencia, y no antes, los jueces no pueden seguir aplicando la excepción de inconstitucionalidad en los casos concretos (A-015/2003, M. Monroy).

Sumado a lo anterior, el Consejo de Estado ha manifestado que la excepción de inconstitucionalidad no puede ser aplicada frente a los actos administrativos de contenido particular y concreto bajo los siguientes argumentos:

Es claro que los actos administrativos de contenido particular y concreto, al no alcanzar la categoría de leyes o normas jurídicas en sentido formal, como que carecen de muchos de sus atributos, no pueden ser objeto de inaplicación por supuesta oposición a la Constitución; de admitirse la posibilidad de aplicar la excepción de inconstitucionalidad respecto de actos administrativos de carácter subjetivo, se daría cabida al desconocimiento de su propia esencia, 
vale decir de medio exceptivo y transitorio para impedir la violación de la Constitución, puesto que en estricto sentido no se estaría dando una inaplicación sino la revocatoria o la extinción de ese acto de contenido particular y concreto, que por obvias razones a futuro no podría ser objeto de aplicación, en pocas palabras perdería toda eficacia. La Registraduría Nacional del Estado Civil, en tanto autoridad administrativa, no es el juez natural de los actos administrativos de contenido electoral, ni por regla general y menos por excepción, de modo que abrogarse una competencia ajena o "inaplicar" un acto administrativo subjetivo por supuestamente hallarlo contrario a la Constitución, claramente demuestra la configuración de una actuación ilegal, sobre todo si se recuerda que el juez de ese tipo de actuaciones es la jurisdicción de lo contencioso administrativo (CE, Quinta, 9 mar. 2006, M. Hernández).

Sobre la procedencia o improcedencia de la aplicación de la excepción de inconstitucionalidad respecto de actos administrativos de contenido particular, así como frente a las sentencias ordinarias, el debate continúa abierto en la medida que no existe todavía un pronunciamiento claro, unificado y homogéneo por parte de la Corte Constitucional que permita decantar un depurado precedente sobre dichas materias; sin embargo, prima facie, resulta excesivo pensar en su uso para estos casos, toda vez que se estaría convirtiendo en abstracto un control que por vocación, naturaleza y características es concreto, reemplazando la facultad de inaplicación por la de anulación, y, poniendo en grave riesgo la seguridad jurídica y sujeción del ordenamiento en su conjunto.
En razón de lo anotado, se puede concluir que a pesar de no existir una reglamentación respecto de la aplicación de la figura sub examine, sí existen unos claros límites o prohibiciones jurisprudenciales a su uso.

\section{Deberes de aplicación}

De manera concomitante al establecimiento de unos límites de aplicación, la jurisprudencia también ha desarrollado unas circunstancias respecto de las cuales la excepción de inconstitucionalidad se constituye en un deber de aplicación, ya que en caso de no ser aplicada se estaría violando de manera directa la Constitución. Al respecto la Corporación se ha pronunciado así:

El artículo 4 constitucional no solo permite, sino que ordena que en cualquier caso de incompatibilidad de la Constitución con otra ley o norma jurídica se aplicarán las disposiciones constitucionales. En esa medida, el funcionario judicial que aplique la excepción de inconstitucionalidad en un caso concreto ve plenamente validados sus pronunciamientos a la luz de la Carta Política (CConst., A-015/2003, M. Monroy).

En este punto, los reiterados pronunciamientos de la Corte al respecto permiten concluir que la excepción de inconstitucionalidad como facultad y deber de los operadores jurídicos, se refiere al fenómeno de la aplicación de las normas de inferior jerarquía en casos concretos, cuando éstas resultan incompatibles, a propósito de dichos casos, con las normas constitucionales (CConst. T-389/2009, H. Sierra). 
En igual sentido el Consejo de Estado ha sostenido:

De manera que cualquier autoridad a quien le corresponda aplicar una norma no solo está legitimada, sino obligada, a abstenerse de hacerlo cuando la encuentra incompatible con la Constitución Política, de modo que de no aplicar en ese evento la excepción de inconstitucionalidad su actuación constituiría una vía de hecho y perdería su validez. En síntesis, la excepción de inconstitucionalidad constituye una excepcional figura de control de constitucionalidad que, en términos del artículo $4^{\circ}$ de la Constitución Política, impone a los funcionarios encargados de aplicar una determinada norma jurídica el deber de inaplicarla en una situación concreta, con efectos sólo respecto de dicha situación, cuando quiera que razonablemente y en términos objetivos advierta que entre dicha norma y la Constitución Política existe incompatibilidad (CE, Quinta, 14 dic. 2006, D. Quiñones).

La no aplicación de la excepción de inconstitucionalidad cuando esta se constituye en un "deber" atribuible a la autoridad judicial, evidentemente podría llegar a configurar una causal específica de procedibilidad de tutela en contra de providencia por violación directa de la Constitución, hecho que se decanta y sistematiza en sentencias tales como la T-774 de 2004 y la C-590 de 2005, las cuales reiteran reglas tales como la fijada por medio de la sentencia T-441 de 2003:

Finalmente se tienen las situaciones en las cuales se incurre en violación directa de la Constitución y de los derechos fundamentales de alguna de las partes. Se trata de las hipó- tesis en las cuales la decisión se apoya en la interpretación de una disposición en contra de la Constitución, y aquellas en las cuales el funcionario judicial se abstiene de aplicar la excepción de inconstitucionalidad cuando la violación de la Constitución resulta manifiesta y la negativa de resolver el punto ante una solicitud expresa por alguna de las partes en el proceso (CConst., T-441/2003, E. Montealegre).

Conforme a lo anterior, de forma enunciativa algunos deberes de aplicación serían los siguientes:

i) Deber de aplicación de la excepción frente a una norma manifiestamente incompatible con la Constitución, en los términos en que fueron expuestos en acápites anteriores.

ii) Deber de aplicación de la excepción frente a una norma formalmente válida y vigente, pero que en su contenido reproduzca otra que haya sido objeto de una declaratoria de inexequibilidad por parte de la Corte Constitucional o de nulidad por parte del Consejo de Estado, en respuesta a una acción pública de inconstitucionalidad o nulidad por inconstitucionalidad según sea el caso. En atención al punto la Corte ha manifestado:

Cuando un juez o un fiscal aplican una disposición formalmente vigente pero que tiene el mismo contenido material de una que ya ha sido declarada inexequible por la Corte Constitucional, es indudable que están violando este precepto constitucional, pues están en la práctica reproduciendo "el contenido material del acto declarado inexequible (CConst., T-669/1996, A. Martínez). 
En calidad de corolario del presente apartado, podemos afirmar que la aplicación de la excepción de inconstitucionalidad resulta ser, como ha sido anotado, una facultad que debe ser utilizada en uso de competencia funcional y atendiendo a unos límites estudiados y descritos en la jurisprudencia; pero al mismo tiempo, se constituye en un deber frente a la existencia de normas claramente incompatibles con la Constitución.

La inadecuada aplicación de la excepción de inconstitucionalidad podría conducir a generar una causal específica de procedibilidad de la tutela en contra de providencias judiciales o actos administrativos o la configuración de conductas punibles como el prevaricato, ya sea por acción u omisión.

\section{CONCLUSIONES}

a) La excepción de inconstitucionalidad es una manifestación de la existencia en nuestro ordenamiento de un modelo "difuso extensivo de constitucionalidad".

b) Esta institución es reconocida por primera vez en nuestro sistema jurídico en el artículo 40 del Acto Legislativo 03 de 1910, el cual fue el producto de la lucha del partido Unión Republicana por reformar la Constitución de 1886.

c) La excepción de inconstitucionalidad es una facultad-deber que se desarrolla a partir de sus dos principales funciones: política (coadyuvando el principio de separación de poderes) y jurídica (garantizando el principio de supremacía de la Constitución). Respecto de esta doble naturale- za que acompaña al control de constitucionalidad anota la profesora Gloria Alcira Robles:

Si bien aquí se ha asumido el carácter jurídico y político del control de constitucionalidad, como derivación de la doble naturaleza de la constitución, en la literatura política y jurídica se observa cierto rechazo a aceptar esta doble naturaleza. La cuestión radica en saber si el establecer límites a la política es en sí mismo una actividad política o si puede mantenerse en los límites de la argumentación jurídica. ¿Por qué resulta injurioso el adjetivo político cuando se hace referencia a una decisión jurídica y por qué resulta antidemocrático suponer que un problema político pueda resolverse a través de la decisión de un juez, a partir de su interpretación de una norma o un conjunto de normas? (2012, pág. 108).

d) La excepción de inconstitucionalidad se caracteriza por tener una competencia in genere de aplicación, generar efectos inter partes, puede ser producto de la solicitud de parte o declarada ex-oficio y obedece a unos criterios objetivos de aplicación.

e) El uso de la excepción se encuentra circunscrito a unos mandatos de promoción (deberes de aplicación) y de abstención (prohibiciones de aplicación).

f) No cuenta con un desarrollo procesal dentro del ordenamiento que indique de forma clara y objetiva cómo se tramita, ejecuta o reconoce. No se explica cómo una institución tan importante para nuestro ordenamiento no tenga unas reglas claras desde el punto de vista procesal para poder ser regentado bajo un criterio objeti- 
vo previamente fijado por el legislador, razón por la cual resulta tan importante la jurisprudencia como la doctrina para llenar estos vacíos en la materia. Al respecto anota el profesor Andrés Velandia:

Sin embargo, creemos que esta institución sustancial por naturaleza, carece de un método procesal o procedimiento para su aplicación, por lo que muchas veces no es utilizada, simplemente por no saber cómo puede aplicarse, o en otras ocasiones puede ser incluso la causa de la violación de los derechos fundamentales de las partes procesales por ser sorpresiva. Nuestra tesis es que debe mantenerse la competencia de todos los jueces para hacer uso de esta importante institución, pero a través de un incidente de control de constitucionalidad previo a la sentencia o de prejudicialidad constitucional, tramitado por el juez del conocimiento en primera instancia, pero si existe recurso de apelación, el mismo sea tramitado por la jurisdicción constitucional, tal como se explicará.

En cuanto a la decisión judicial de este modelo, no cabe duda que debe ser a través de autos y no de sentencias, habida cuenta que se trata de una decisión incidental, con carácter prejudicial a la sentencia proferida dentro del proceso ordinario (2013, pág. 137).

g) El estudio del derecho procesal constitucional permite la permanente reflexión y debate de los mecanismos o instrumentos por medio de los cuales se posibilita la efectividad o materialidad de la Constitución, la cual por interpretación extensiva (bloque de constitucionalidad) cada vez se hace más compleja e "inasible". h) Solo con la garantía real de los derechos humanos consagrados en la Constitución se podrá hablar de su existencia viva y material. Hasta que esto no sea una realidad, seguirá siendo un catálogo de ilusiones y promesas aplazadas de un pueblo soberano pero excluido e invisible.

\section{Referencias}

Asamblea Nacional de Colombia. Acto Legislativo 03 de 1910.

Consejo de Estado. Sala de Consulta y Servicio Civil. Radicación 1999 (C. P.: William Zambrano Cetina; mayo 20 de 2010).

Consejo de Estado. Sentencia Sección Cuarta. Rad 5996 (C. P.: Delio Gómez Leyva; julio 14 de 1995).

Consejo de Estado. Sentencia Sección Cuarta. Rad. 16718 (C. P.: Martha Teresa Briceño de Valencia; octubre 26 de 2009).

Consejo de Estado. Sentencia Sección Quinta. Rad. 3853 (C. P.: María Nohemí Hernández Pinzón; marzo 9 de 2006).

Consejo de Estado. Sentencia Sección Quinta. Rad. 3975 (C. P: Darío Quiñonez Pinilla; diciembre 14 de 2006).

Constituyente. (1991). Constitución Política de Colombia.

Corte Constitucional de Colombia. Auto 015 de 2003 (M. P.: Marco Gerardo Monroy Cabra; febrero 4 de 2003). 
Corte Constitucional de Colombia. Sentencia C-600 de 1998 (M. P.: José Gregorio Hernández; octubre 21 de 1998).

Corte Constitucional de Colombia. Sentencia C-037 de 2000 (M. P.: Vladimiro Naranjo Mesa; enero 26 de 2000).

Corte Constitucional de Colombia. Sentencia C-803 de 2006 (M. P.: Jaime Córdoba Triviño; septiembre 27 de 2006).

Corte Constitucional de Colombia. Sentencia C-122 de 2011 (M. P.: Juan Carlos Henao Pérez; marzo 1 de 2011).

Corte Constitucional de Colombia. Sentencia SU-132 de 2013 (M. P.: Alexei Julio Estrada; marzo 13 de 2013).

Corte Constitucional de Colombia. Sentencia T-006 de 1994 (M. P.: Vladimiro Naranjo Mesa; enero 17 de 1994).

Corte Constitucional de Colombia. Sentencia T-614 de 1992 (M. P.: José Gregorio Hernández; diciembre 15 de 1992).

Corte Constitucional de Colombia. Sentencia T-063 de 1995 (M. P.: José Gregorio Hernández Galindo; febrero 22 de 1995).

Corte Constitucional de Colombia. Sentencia T-669 de 1996 (M. P.: Alejandro Martínez Caballero; noviembre 28 de 1996).
Corte Constitucional de Colombia. Sentencia T-357 de 2002 (M. P.: Eduardo Montealegre Lynett; mayo 9 de 2002).

Corte Constitucional de Colombia. Sentencia T-441 de 2003 (M. P.: Eduardo Montealegre Lynett; mayo 29 de 2003).

Corte Constitucional de Colombia. Sentencia T-808 de 2007 (M. P.: (E) Catalina Botero Marino; octubre 1 de 2007).

Corte Constitucional de Colombia. Sentencia T-389 de 2009 (M. P.: Humberto Antonio Sierra Porto; mayo 28 de 2009).

Guastini, R. (2007). Sobre el concepto de Constitución. En M. Carbonell, Teorías del neoconstitucionalismo (págs. 15-29). Madrid: Trotta.

Hamilton, A., Madison, J., Jay, J., Tunc, A. y Jezè, A. (1988). Le Fédéraliste. París: Económica.

Maya, M. (2012). Discordia, reforma constitucional y excepción de inconstitucionalidad. Revista de Estudios Sociales, 118-128.

North, D. (1990). Institutions, Institucional Change and Economic Performance. Cambridge: Cambrigde University Press.

Pulido, F. (2011). Control constitucional abstracto, concreto, maximalista y minimalista. Prolegómenos, XIV(27), 165-180.

Restrepo, C. E. (1972). Orientación Republicana. Bogotá: Banco Popular. 
Robles, G. (2012). El control constitucional y sus límites. Bogotá: Grupo Editorial Ibáñez.

Sanín, J. (1971). La defensa judicial de la Constitución. Bogotá: Editorial Temis.

Sierra, H. (2013). Los factores que determinan las particularidades de la interpretación constitucional en Colombia. En J. C. Henao, Diálogos constitucionales de Colombia con el mundo: VII encuentro de la jurisdicción constitucional (págs. 265-278). Bogotá: Corte Constitucional de Colombia/Universidad Externado de Colombia.

Tobo, J. (1999). La Corte Constitucional y el control de constitucionalidad en Colombia. Bogotá: Ediciones Jurídicas Gustavo Ibáñez.
Tocqueville, A. (1981). De la démocratie en Amérique. Paris: Centre National des lettres.

Upegui, J. (2009). Doce tesis en torno al concepto de Estado social de derecho: discurso jurisprudencial, elementos, usos. Bogotá. Universidad Externado de Colombia/Instituto de Estudios Constitucionales Carlos Restrepo Piedrahita.

Velandia, E. (Coord.). (2013). Derecho Procesal Constitucional. Bogotá: VC Editores Ltda./ Asociación Colombiana de Derecho Procesal Constitucional. 